\title{
Applying the Weibull and Stüssi Methods that Derive Reliable Wöhler Curves to Historical German Bridges
}

\author{
Paul Dario Toasa Caiza, Dr.Eng. ${ }^{1}$; Thomas Ummenhofer, Dr.Eng. ${ }^{2}$; \\ José A. F. O. Correia, Ph.D. ${ }^{3}$; and Abilio De Jesus, Ph.D. ${ }^{4}$
}

\begin{abstract}
Preserving the structural integrity of historical bridges made of wrought iron is a mandatory technical requirement in several countries in Europe. A reliable fatigue lifetime estimation of theses bridges allows for proposal of adequate maintenance policies to keep these historical structures as part of the historical legacy for the next generations. In this paper, fatigue data of German bridges built between 1850 and 1900 are considered. The Weibull model of Castilllo and the model of Stüssi to depict the Wöhler curves and estimate the fatigue limit are applied. Their results are compared with those from the linear model of Basquin, which is used in international standards.
\end{abstract}

Author keywords: Fatigue; Lifetime; Estimation; Weibull; Stüssi.

\section{Introduction}

Modeling the fatigue of materials has been a technical challenge for engineers, phyisicians, and mathematicians since the late nine teenth century. The interest on this research topic increased during the Industrial Revolution. [The period of time covered by the In dustrial Revolution varies with different historians. Hobsbawm (1999) held that it "broke out" in Britain in 1789 and was not fully felt until 1848, whereas Ashton (1998) held that it occurred roughly between 1760 and 1830.]

The research of August Wöhler (Soltau, June 22, 1819 to Hannover, March 21, 1914, German engineer, Royal Obermaschi nenmeister of the Niederschlesisch Mährische Railways in Frank furt an der Oder) on railway axles established the fundaments of fatigue tests whose results currently are represented as $S N$ curves. To carry out these experiments, Wöhler designed a rotating bending machine, which ran at a very low frequency. Wöhler also designed machines that performed axial bending and torsion tests on different notched and unnotched specimens. In 1870, Wöhler published the results, which contained his conclusions (Wöhler 1870) and often are called Wöhler's laws.

One alternative for predicting the fatigue life of steel struc tures is based on the Wöhler curves, which are obtained from

${ }^{1}$ Scientific Employee, Karlsruher Institut für Technologie Stahl und Leichtbau, Versuchsanstalt für Stahl, Holz und Steine, Karlsruher Institut für Technologie, Otto Ammann Platz, Karlruhe 76131, Germany (corre sponding author). ORCID: https://orcid.org/0000 00024328 4504. Email: paul.toasa@kit.edu

${ }^{2}$ Professor and Director of the "Versuchsanstalt für Stahl, Holz und Steine," Karlsruher Institut für Technologie Stahl und Leichtbau, Versuchsanstalt für Stahl, Holz und Steine, Karlsruher Institut für Technologie, Otto Ammann Platz, Karlruhe 76131, Germany. Email: thomas.ummenhofer@kit.edu

${ }^{3}$ Professor, Faculty of Engineering, Univ. of Porto, Rua Dr. Roberto Frias, Porto 4200 465, Portugal. Email: jacorreia@inegi.up.pt

${ }^{4}$ Professor, Faculty of Engineering, Univ. of Porto, Rua Dr. Roberto Frias, Porto 4200 465, Portugal. Email: ajesus@fe.up.pt experimental fatigue data. Considering the stress based approach, several models have been proposed to represent the Wöhler curves (Toasa Caiza 2018).

The estimation of the fatigue life of historical steel bridges has been studied by several researchers (e.g., Helmerich 2005; Mang and Bucak 1991, 1993; Pedrosa et al. 2019; Mayorga et al. 2017).

In this paper, two applications for modeling the Wöhler curves are presented. The experimental fatigue data were obtained by test ing the main girders of antique bridges built between 1850 and 1900. Two methods to depict the Wöhler curves are applied, and their results are compared with those from the linear model of Basquin (1910), which is based on the Wöhler results and used in international standards.

\section{Basquin Model of 1910}

The linear model of Basquin (1910) given by the equation

$$
\log N=A-B \log \Delta \sigma, \quad \Delta \sigma \geq \Delta \sigma_{\infty}
$$

has been applied to depict the Wöhler curves (Schijve 2009) on the finite life fatigue zone by international standards such as Eurocode 3 (Sedlacek et al. 2005; CMC 2010), ISO 12107 (ISO 2008), and ASTM E739 10 (ASTM 2015).

The estimation of the parameters $A$ and $B$ can be done by ap plying standard least squares methods (e.g., Toasa Caiza 2008b). It is assumed that the lifetime $N_{i}$ and the stress range $\Delta \sigma_{i}$ follow a normal or $t$ student distribution, so that the stress range and its con fidence intervals can be estimated on the high cycle fatigue (HCF) zone (Spindel and Haibach 1979). In this way the percentile curves of the Basquin model can be determined in order to facilitate its comparison with respect to the Weibull and Stüssi models.

Unfortunately, this model presents some limitations. One the one hand, because of the assumed linear relationship between the stress range and the number of load cycles, this model is neither suitable to extrapolate the Wöhler curves from the finite life region to the HCF region nor able to provide an estimation of the fatigue limit. A linear model allows one to make estimations or extrapo lations only within the experimental frame and range because the geometry of the mentioned relationship can change beyond this re gion. And in fact, this is the case of the fatigue life. 


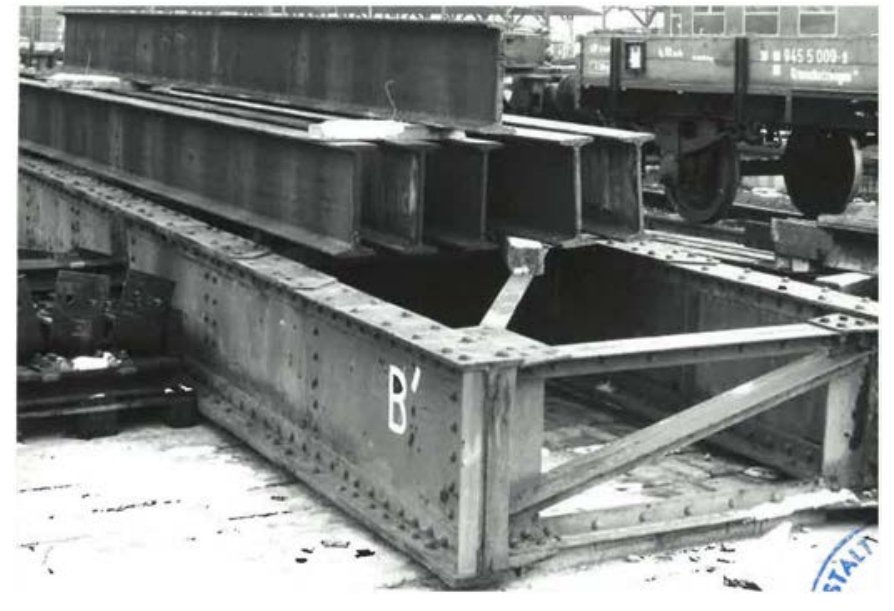

Fig. 1. Main girders of the Dingolfing Bridge. (Reproduced with per mission from Bähre and Kosteas 1979.)

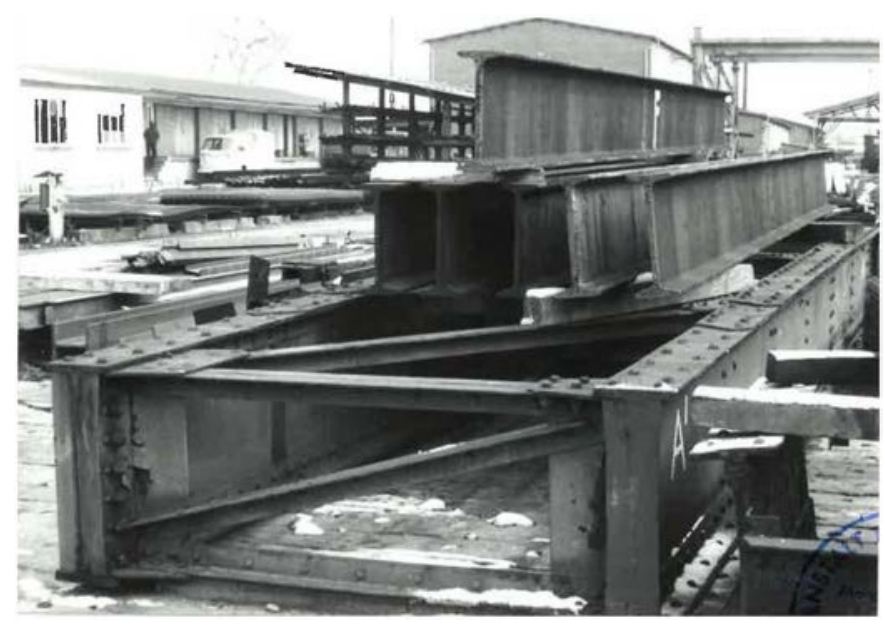

Fig. 2. Main girders of the Loiching Bridge. (Reproduced with permis sion from Bähre and Kosteas 1979.)

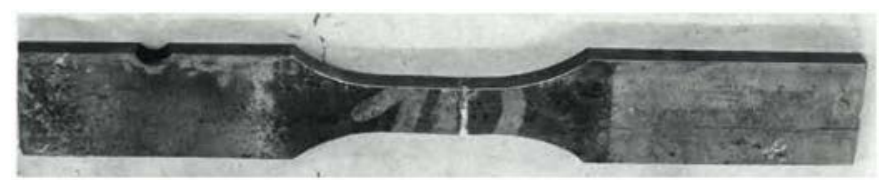

Fig. 3. Geometry of the samples for the fatigue tests. (Reproduced with permission from Bähre and Kosteas 1979.)

Table 1. German historical bridge data on fatigue failures $\left(\begin{array}{ll}R & 0.1\end{array}\right)$

\begin{tabular}{lrrrr}
\hline$\Delta \sigma(\mathrm{MPa})$ & $N$ & $N$ & $N$ & $N$ \\
\hline 288 & 124,900 & 156,700 & 197,000 & \\
261 & 137,000 & 194,000 & 252,400 & 263,800 \\
& 297,300 & 437,400 & & \\
243 & 373,200 & & & \\
225 & 599,200 & & & \\
216 & 246,600 & 689,800 & 779,500 & 872,200 \\
& $1,031,000$ & & & \\
207 & $1,205,800$ & $1,268,120$ & $1,602,200$ & $1,886,800$ \\
& $2,049,500$ & $2,139,900$ & & \\
198 & $1,193,400$ & $1,596,300$ & $2,179,700$ & \\
\hline
\end{tabular}

Table 2. German historical bridge data of runouts $\left(\begin{array}{ll}R & 0.1\end{array}\right)$

\begin{tabular}{lccr}
\hline$\Delta \sigma(\mathrm{MPa})$ & $N$ & $N$ & \multicolumn{1}{c}{$N$} \\
\hline 216 & $3,287,420$ & & \\
207 & $2,278,100$ & $2,451,600$ & $2,956,700$ \\
198 & $3,348,400$ & $3,640,420$ & $12,335,620$ \\
189 & $2,000,000$ & $8,119,200$ & $8,292,100$ \\
\hline
\end{tabular}

Table 3. German historical bridge data of runouts and their retests $\left(\begin{array}{ll}R & 0.1\end{array}\right)$

\begin{tabular}{lccrrr}
\hline$\Delta \sigma_{1}(\mathrm{MPa})$ & $N_{1}$ & $\Delta \sigma_{2}(\mathrm{MPa})$ & \multicolumn{1}{c}{$N_{2}$} & \multicolumn{1}{c}{$N_{2}$} & \multicolumn{1}{c}{$N_{2}$} \\
\hline 261 & 100,000 & 189 & 715,800 & $2,052,400$ & $1,660,400$ \\
& & & $1,088,100$ & $2,519,700$ & $2,407,900$ \\
& & 225 & 249,000 & 938,700 & 573,000 \\
& & & 919,700 & 539,300 & 573,000 \\
189 & $2,000,000$ & 261 & 134,100 & 156,500 & 196,000 \\
& & & 217,400 & 254,500 & 395,600 \\
& & & 543 & 237,900 & 427,300 \\
& & & $1,080,600$ & $1,396,900$ & $1,650,500$ \\
\hline
\end{tabular}

Table 4. German historical bridge estimations of the fatigue life $\left(\begin{array}{ll}N \quad 5 \times 10^{6}\end{array}\right)$

\begin{tabular}{lcc}
\hline Model & Probability $(\%)$ & $\Delta \sigma(\mathrm{MPa})$ \\
\hline EC3 & 5 & 66.3 \\
Greiner & 5 & 74.9 \\
Basquin & 5 & 148.9 \\
Weibull & 5 & 173.9 \\
Stüssi & 5 & 127.9 \\
\hline
\end{tabular}

For this reason, in order to overcome this limitation, an arbitrary knee point on the linear regression is suggested where the slope changes (Hobbacher 2009, 2010; CMC 2010). This point represents the classical transition from the endurance line to the fatigue limit, and its existence is assumed and based on empirical knowledge (Hobbacher 2010). On the other hand, from the statistical point of view, it has been proved that the arbitrary assumption of a normal or log normal distribution in this model is not suitable to model fatigue data (Hobbacher 2010; Castillo and Fernández Canteli 2009).

\section{Weibull Model of Castillo et al.}

An alternative model based on a Weibull distribution $W(a, b, c)$ is given by

$p=1-\exp \left\{-\left[\frac{(\log N-B)(\log \Delta \sigma-C)-a}{b}\right]^{c}\right\} ;$

$(\log N-B)(\log \Delta \sigma-C) \geq a$

where $p=$ probability of fatigue failure (Castillo and Fernández Canteli 2009). This model depends on two geometrical parameters, namely $B$ and $C$, and three Weibull parameters, namely $a, b$, and $c$. The geometrical parameters are estimated by solving a nonlinear problem (Castillo et al. 2008), and the Weibull parameters can be estimated by the methods suggested by Toasa Caiza and Ummenhofer (2011) or Gupta and Panchang (1989).

The model allows one to consider the runouts and their sub sequent retests in the statistical evaluation of the experimental data (Toasa Caiza and Ummenhofer 2018b). Moreover, it describes properly the asymptotic behavior of the fatigue life in VHCF. How ever, in LCF the application of this model is not suitable. 


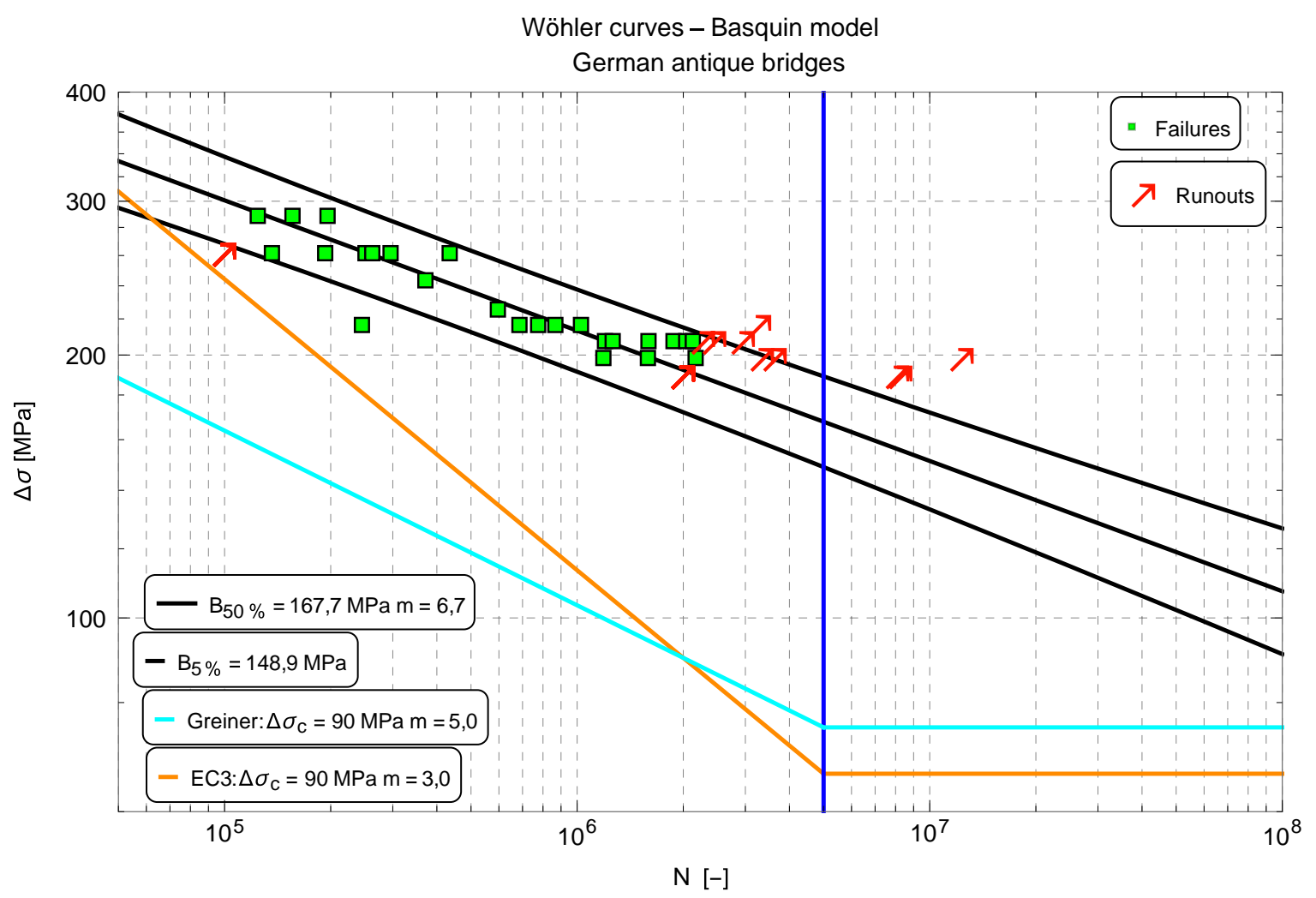

Fig. 4. German historical bridge Wöhler curves for a fatigue failure probability of 5\%, 50\%, and 95\%: Basquin model.

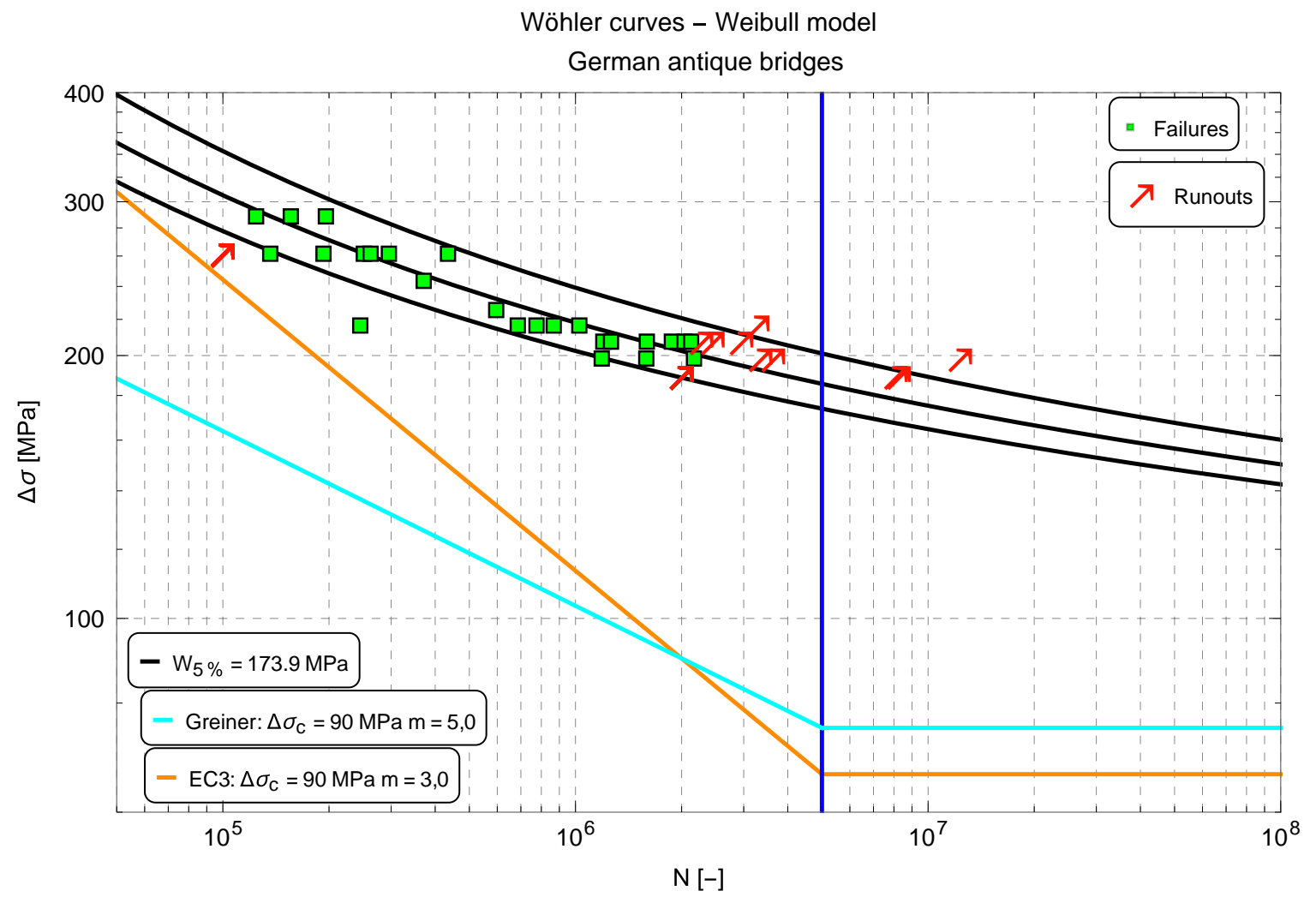

Fig. 5. German historical bridge Wöhler curves for a failure probability of 5\%, 50\%, and 95\%: Weibull model. 


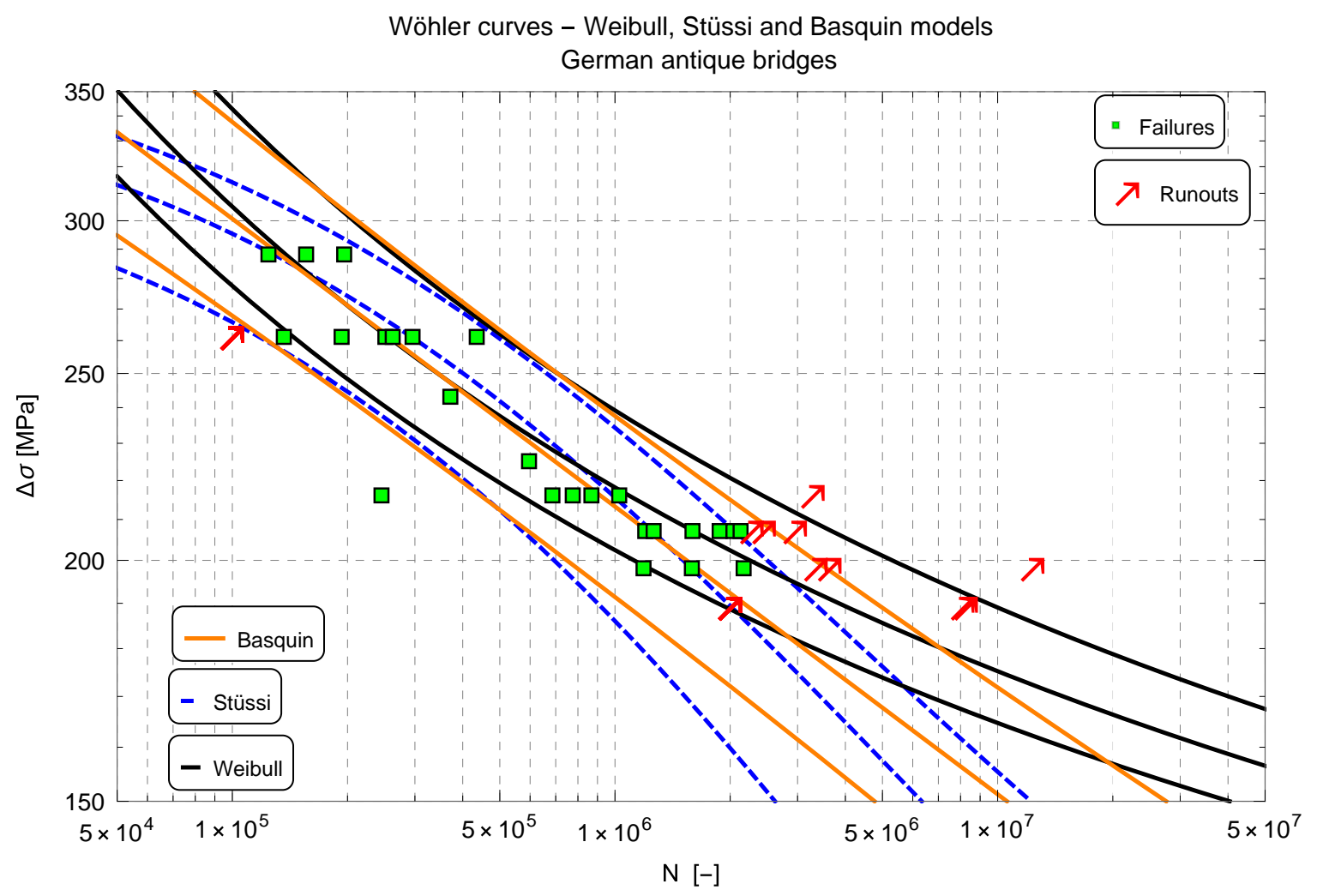

Fig. 6. German historical bridge Wöhler curves for a failure probability of 5\%, 50\%, and 95\%: Basquin, Stüssi, and Weibull models.

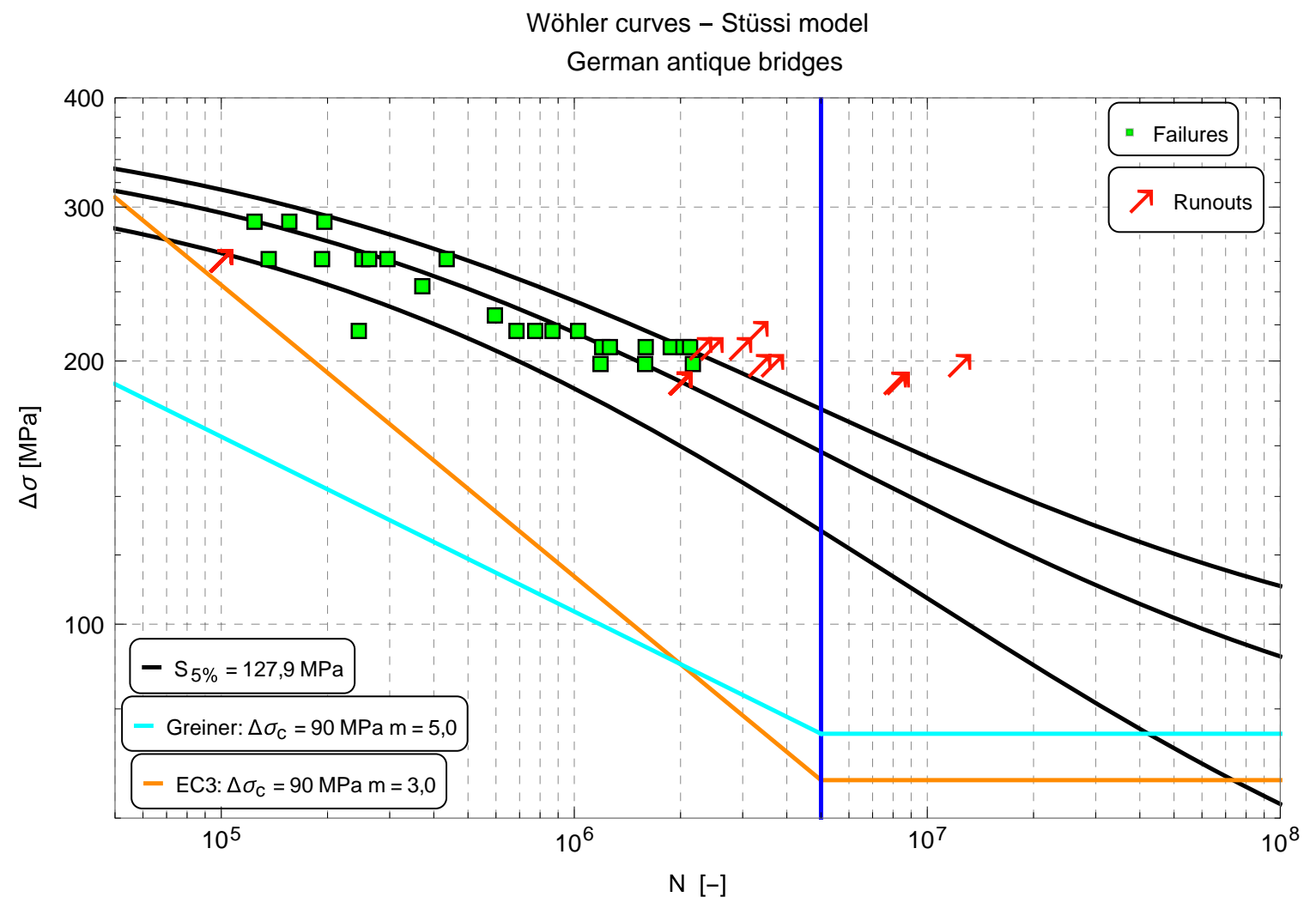

Fig. 7. German historical bridge Wöhler curves for a failure probability of 5\%,50\%, and 95\%: Stüssi model. 


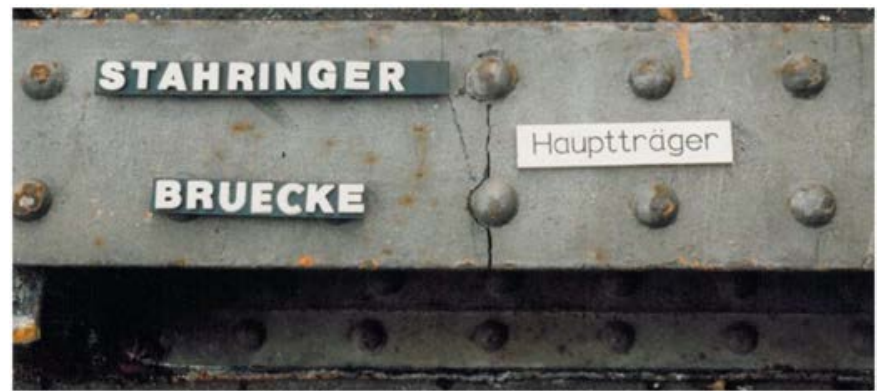

Fig. 8. Main girder taken from the Stahringer Bridge. (Reproduced with permission from Bähre and Kosteas 1979.)

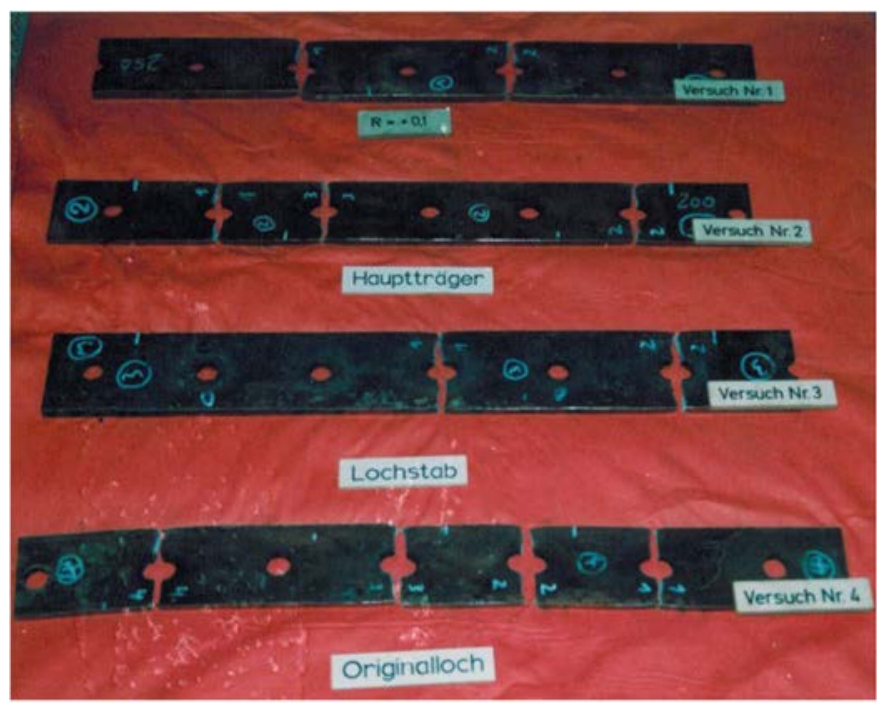

Fig. 9. Specimens taken from the Stahringer Bridge. (Reproduced with permission from Bähre and Kosteas 1979.)

Table 5. Stahringer Bridge (1895) Fatigue data of failures and runouts $\left(\begin{array}{ll}R & 0,1\end{array}\right)$

\begin{tabular}{lrrrrr}
\hline$\Delta \sigma(\mathrm{MPa})$ & \multicolumn{1}{c}{$N$} & \multicolumn{1}{c}{$N$} & \multicolumn{1}{c}{$N$} & \multicolumn{1}{c}{$N$} & \multicolumn{1}{c}{$N$} \\
\hline 225 & 38,927 & 46,474 & & & \\
180 & 112,302 & 138,322 & 142,491 & 133,710 & 127,800 \\
& 235,782 & 302,732 & 133,500 & 133,840 & 289,800 \\
& 330,300 & & & & \\
144 & 523,200 & 398,319 & 554,726 & 496,652 & 647,726 \\
& 897,183 & 885,600 & $1,200,640$ & 661,550 & 683,264 \\
& 739,415 & 827,473 & 989,000 & 456,020 & 456,480 \\
& 292,680 & 309,570 & 355,100 & & \\
126 & $1,333,748$ & $1,904,087$ & $1,964,597$ & 766,126 & $1,236,622$ \\
& $1,514,865$ & $1,272,776$ & $1,313,096$ & $1,689,579$ & $1,882,968$ \\
& 775,688 & $1,084,235$ & $1,334,498$ & $1,401,002$ & \\
108 & $2,980,233$ & $3,504,216$ & $5,484,220$ & $17,804820^{\mathrm{a}}$ & \\
\hline
\end{tabular}

${ }^{\text {a }}$ The experiment for this entry was a runout.

Table 6. Stahringer Bridge (1895) estimations of the fatigue life $(N$ $5 \times 10^{6}$ )

\begin{tabular}{lcc}
\hline Model & Probability $(\%)$ & $\Delta \sigma(\mathrm{MPa})$ \\
\hline EC3 & 5 & 66.3 \\
Greiner & 5 & 74.9 \\
Basquin & 5 & 90.6 \\
Weibull & 5 & 100.8 \\
Stüssi & 5 & 81.3 \\
\hline
\end{tabular}

\section{Stüssi Model}

The following model is based on the Stüssi equation (Stüssi 1955), and it can be identified as a Weibull model in which a correction is introduced to account for the low cycle fatigue (LCF) effect:

$$
p=1-\exp \left\{-\left[\frac{\Delta \sigma-\frac{R_{m}+\alpha N^{\beta} \Delta \sigma_{\infty}}{1+\alpha N^{\beta}}-a}{b}\right]^{c}\right\}
$$

The ultimate tensile strength $R_{m}$ and the fatigue limit $\Delta \sigma_{\infty}$ are assumed to be known or already estimated, the parameters $\alpha$ and $\beta$ are estimated by applying a linear regression, and the Weibull parameters $a, b$, and $c$ can be estimated as in the previous model (Toasa Caiza and Ummenhofer 2018a). This model describes properly the fatigue life in LCF, but in very high cycle fatigue (VHCF) it is much more conservative than the models of Basquin (1910) and Castillo and Fernandez Canteli (2009).

\section{Application to German Historical Bridges}

The aforementioned models are applied on the experimental data obtained from seven German antique bridges made of wrought iron and built between 1850 and 1900. The obtained results are com pared with the fatigue strength curve of Eurocode $3(m=3)$, the curve proposed by Greiner et al. (2007) $(m=5)$, and the model of Basquin applied in ISO 12107 and ASTM E739 10.

\section{German Bridges 1850-1900}

In a research project financed by the German Federal Railway [Deutsche Bundesbahn (DB)], 59 identical samples taken from the main girders of six antique bridges: Loiching, Dingolfing, and Pilsting Plattning (42.93 km), Landshut Plattning (6.086 and $7.745 \mathrm{~km}$ ), and Weiden Hof were tested (Bähre and Kosteas 1979). The main girders of the Dingolfing and Loiching Bridges are shown in Figs. 1 and 2. The geometry of the samples is shown in Fig. 3.

The experimental data are given in Tables 13.

At 5 million load cycles, the estimations of the $5 \%$ quantile of the fatigue lifetime obtained by applying the Basquin, Weibull, and Stüssi models are higher than the proposals from Eurocode 3 and Greiner [Table 4]. The slope given by the Basquin model $(m=6.7)$ differs from the slope given in Eurocode 3 and the suggested one by Greiner (Fig. 4).

Because the Weibull model considers the runouts and their retests, the asymptotic behavior of the Wöhler curves in HCF and VHCF regions is properly described (Fig. 5). Moreover, the estimation of the fatigue lifetime and fatigue limit $\left(\Delta \sigma_{\infty}=\right.$ 61.4 MPa) are the highest (Fig. 6). By applying the Stüssi model, the Wöhler curves in LCF region, where the plastic behavior pre vails, are properly described (Fig. 7).

\section{Stahringer Bridge Built in 1895}

For the second application, 49 experiments performed on speci mens cut out from the main girders with original perforations of the Stahringer bridge are considered (Toasa Caiza 2008a, 2018). One main girder and the corresponding taken specimens are shown in Figs. 8 and 9. The experimental data are given in Table 5.

In this case, the estimations of the fatigue lifetime at 5 million load cycles obtained by applying the Basquin, Weibull, and Stüssi models are higher than the proposals from Eurocode 3 and from Greiner as well [Table 6]. 


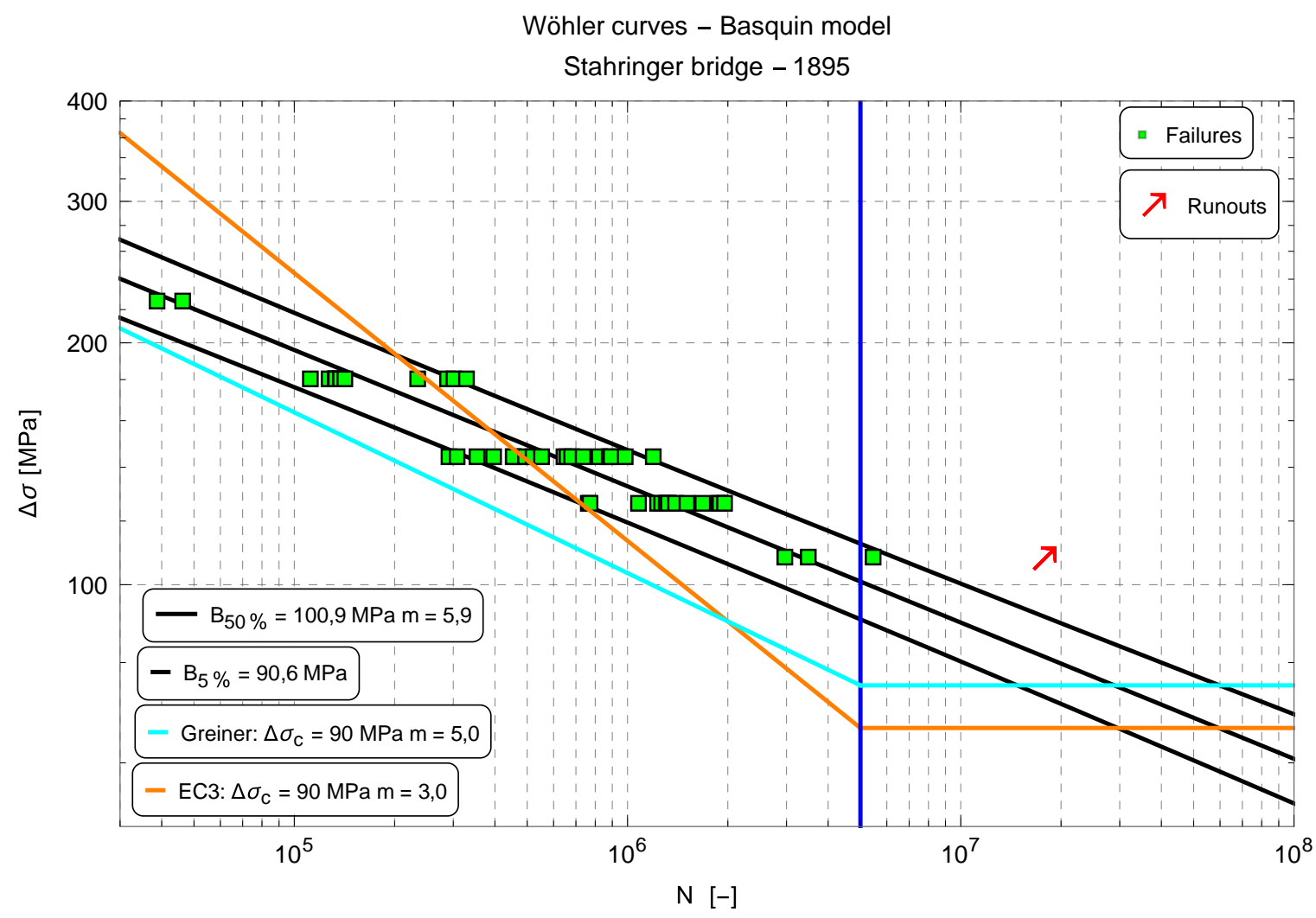

Fig. 10. Stahringer Bridge (1895) Wöhler curves for a failure probability of 5\%,50\%, and 95\%: Basquin model.

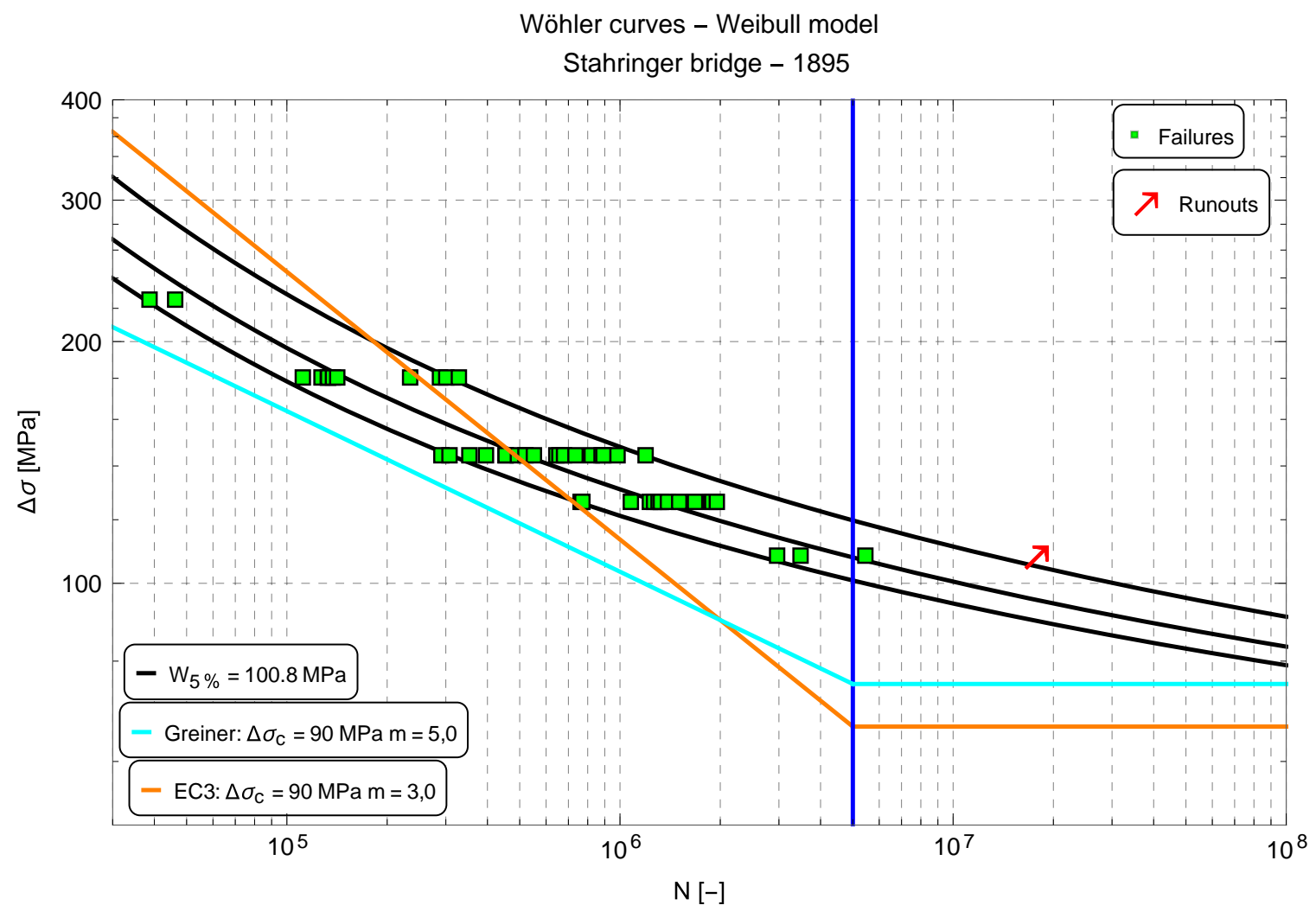

Fig. 11. Stahringer Bridge (1895) Wöhler curves for a failure probability of 5\%, 50\%, and 95\%: Weibull model. 


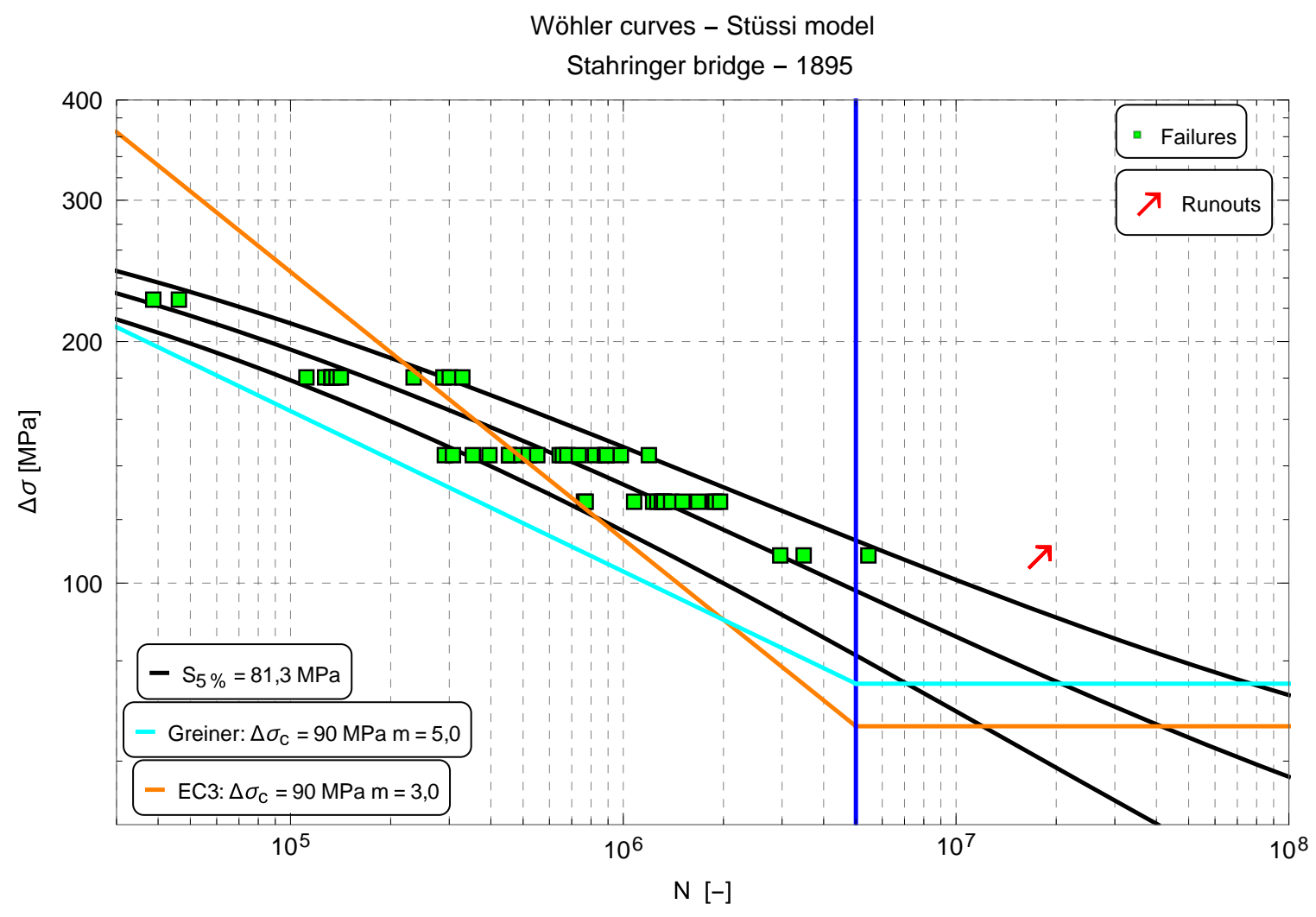

Fig. 12. Stahringer Bridge (1895) Wöhler curves for a failure probability of 5\%, 50\%, and 95\%: Stüssi model.

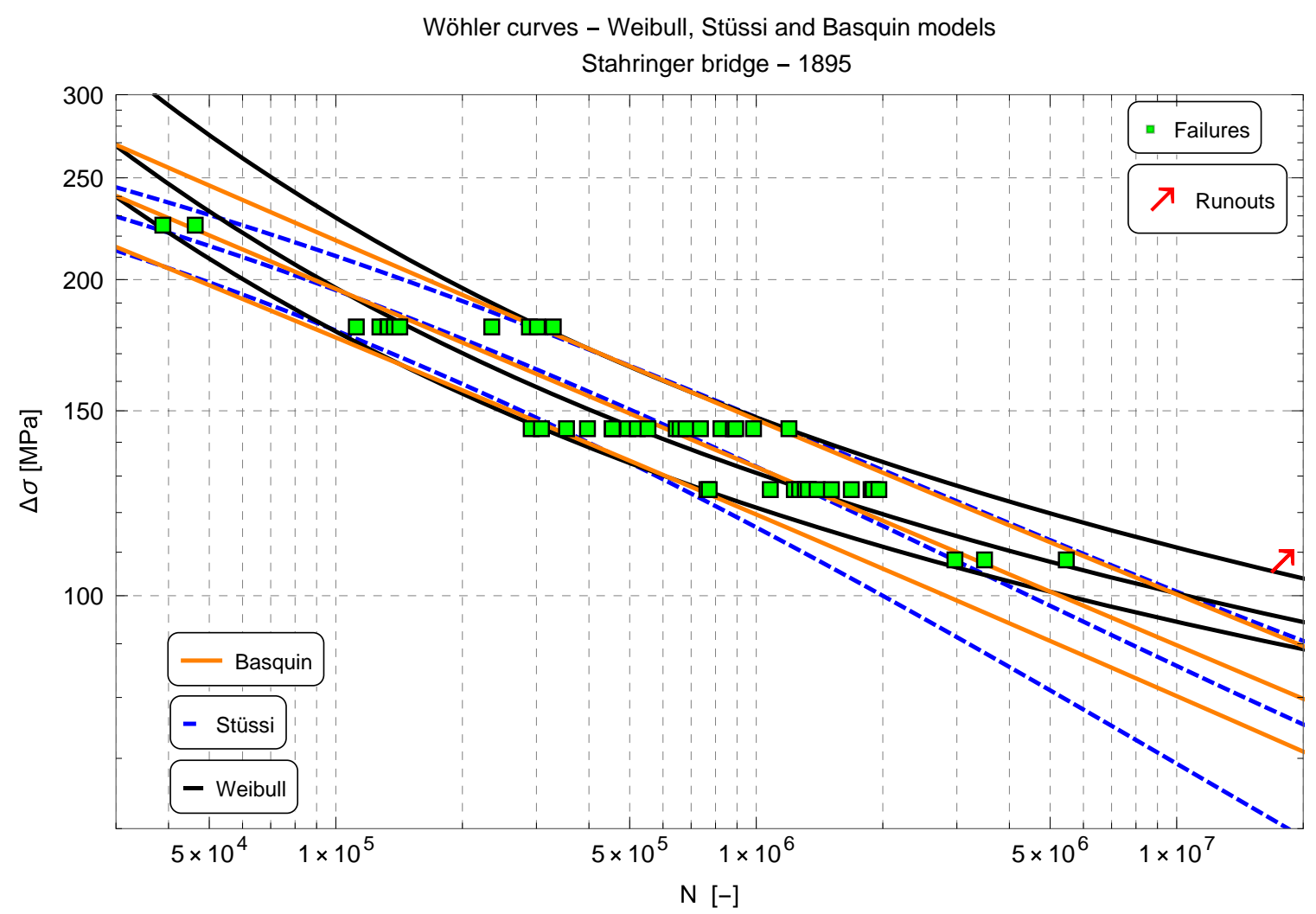

Fig. 13. Stahringer Bridge (1895) Wöhler curves for a failure probability of 5\%, 50\%, and 95\%: Basquin, Stüssi, and Weibull models. 
On the one hand, the slope given by the Basquin model $(m=5.9)$ is revealed to be similar to the slope $(m=6.0)$ obtained for single shear riveted connections of Pedrosa et al. (2019). This similarity does not depend on the stress ratio $R$ of the experiments. In fact, in the Basquin model, $R$ affects only the vertical displace ment of the regression. On the other hand, it differs from the slope given in Eurocode $3(m=3.0)$ and the suggested one by Greiner $(m=5.0)$ (Fig. 10).

Even though there is one runout, the Weibull model describes properly the asymptotic behavior of the Wöhler curves in HCF and VHCF regions (Fig. 11). The estimated fatigue limit $\Delta \sigma_{\infty}$ is 29.07 MPa when only the fatigue failures are considered, and it is $28.59 \mathrm{MPa}$ when the fatigue failures and the runout are consid ered (Toasa Caiza and Ummenhofer 2018b). These estimations of the fatigue limit are similar to the estimated fatigue limit of 30.14 MPa obtained from other antique European bridges such as the Eiffel Bridge (Portugal), Fäo Bridge (Portugal), and the bridge over the Adour River (France) (Mayorga et al. 2017). This particu lar fact requires attention because the corresponding stress ratios $R$ are different. For this reason, additional investigations are in order to establish the effect of the stress ratio. Moreover, the estimation of the fatigue lifetime and fatigue limit are the highest (Fig. 13).

In the LCF region, the Stüssi model describes properly the geometry of the Wöhler curves (Fig. 12).

\section{Conclusions}

The two applications presented in this paper show that the appli cation of the linear Basquin model or assigning a predetermined slope to the Wöhler curves is not appropriate to estimate fatigue life of an historical riveted structure.

On the one hand, the Weibull model describes properly the asymptotic behavior of the fatigue lifetime in the VHCF regime; however, this model does not help to make an estimation in the LCF regime.

On the other hand, because the Stüssi model considers the ulti mate tensile strength, it allows one to describe the fatigue lifetime in the LCF regime; however, in the HCF and VHCF regimes, this model is more conservative than the Weibull model.

Based on the experimental results and aforementioned compar isons, it can be concluded that a suitable estimation of the fatigue life can be made by applying the Weibull model in both the HCF and VHCF regimes. The same applies for the Stüssi model but only in the LCF regime.

\section{Data Availability Statement}

The fatigue experimental data of the historical bridges considered in this paper are available from the corresponding author upon rea sonable request.

\section{References}

Ashton, T. S. 1998. The industrial revolution, 1760 1830. Oxford, UK: Oxford University Press.

ASTM. 2015. Standard practice for statistical analysis of linear or linear ized stress life $(S N)$ and strain life $(\varepsilon N)$ fatigue data. ASTM E739 10. West Conshohocken, PA: ASTM.

Bähre, R., and D. Kosteas. 1979. Einflu $\beta$ der Vorbelastung auf die Rest nutzungsdauer schweiß eisener Brücken. Rep. No. 7496. Karlsruhe, Germany: Karlsruher Institut für Technologie.

Basquin, O. H. 1910. "The exponential law of endurance tests." Am. Soc. Test. Mater. Proc. 10: 625630.
Castillo, E., and A. Fernández Canteli. 2009. A unified statistical method ology for modeling fatigue damage. New York: Springer.

Castillo, E., A. Fernández Canteli, H. Pinto, and M. López Aenlle. 2008. "A general regression model for statistical analysis of strain life fatigue data." Mater. Lett. 62 (21 22): 3639 3642. https://doi.org/10.1016/j .matlet.2008.04.015.

CMC (CEN Management Centre). 2010. Eurocode 3: Design of steel structures, Part 1 9: Fatigue. EN 19931 9:2005. Brussels, Belgium: CMC.

Greiner, R., A. Taras, and H. Brunner. 2007. "Statistisch begründete Festigkeitskennwerte genieteter Bauteile statische Festigkeit und Wöhlerlinienkatalog." Stahlbau 76 (8): 537 552. https://doi.org/10 .1002/stab.200710056.

Gupta, V. G., and R. C. Panchang. 1989. "On the determination of three parameter Weibull MLE's.” Comm. Stat. Simul. Comput. 18 (3): 1037 1057. https://doi.org/10.1080/03610918908812805.

Helmerich, R. 2005. Alte Stähle und Stahlkonstruktionen. Materialunter suchungen, Ermüdungsversuche an originalen Brückenträgern und Messungen von 1990 bis 2003. Rep. No. 271. Berlin: Bundesanstalt für Materialforschung und prüfung.

Hobbacher, A. F. 2009. "The new IIW recommendations for fatigue assess ment of welded joints and components A comprehensive code re cently updated." Int. J. Fatigue 31 (1): 50 58. https://doi.org/10 .1016/j.ijfatigue.2008.04.002.

Hobbacher, A. F. 2010. "New developments at the recent update of the IIW recommendations for fatigue of welded joints and components." Steel Constr. 3 (4): 231 242. https://doi.org/10.1002/stco.201010030.

Hobsbawm, E. 1999. Industry and empire: The birth of the industrial rev olution. New York: The New Press.

ISO. 2008. Metallic materials Fatigue testing Statistical planning and analysis of data. ISO 12107:2012. Washington, DC: ISO.

Mang, F., and O. Bucak. 1991. "Remaining fatigue life of old steel bridges Theoretical and experimental investigations on railway bridges." In Proc., Int. Symp. on Fatigue and Fracture in Steel and Concrete Structures, Madras, India, 971 991. Oxford, UK: Structural Engineering Research Centre, IBH Publishing.

Mang, F., and O. Bucak. 1993. "Application of the S N line concept for the assessment of the remaining fatigue life of old bridge structures." Chap. 85 in Bridge management 2, 821 832. London: Thomas Telford Publishing.

Mayorga, L. G., S. Sire, J. A. Correia, A. M. D. Jesus, C. Rebelo, A. Fernández Canteli, M. Ragueneau, and B. Plu. 2017. "Statistical evalu ation of fatigue strength of double shear riveted connections and crack growth rates of materials from old bridges." Eng. Fract. Mech. 185 (Nov): 241 257. https://doi.org/10.1016/j.engfracmech.2017.05.039.

Pedrosa, B., J. A. Correia, C. Rebelo, G. Lesiuk, A. M. D. Jesus, A. A. Fernández Canteli, M. Duda, R. Calçada, and M. Veljkovic. 2019. "Fatigue resistance curves for single and double shear riveted joints from old Portuguese metallic bridges." Eng. Fail. Anal. 96 (Feb): 255 273. https://doi.org/10.1016/j.engfailanal.2018.10.009.

Schijve, J. 2009. Fatigue of structures and materials. New York: Springer.

Sedlacek, G., A. Hobbacher, A. Nussbaumer, and J. Stötzel. 2005. "1st draft of the background document prEN 19931 9." Eurocode 3: Design of steel structures. Brussels, Belgium: European Committee for Standardization.

Spindel, J., and E. Haibach. 1979. "The method of maximum likelihood applied to the statistical analysis of fatigue data." Int. J. Fatigue 1 (2): 81 88. https://doi.org/10.1016/0142 1123(79)90012 4.

Stüssi, F. 1955. Tragwerke aus Aluminium. New York: Springer.

Toasa Caiza, P. D. 2008a. Ermüdungsversuche an alten Stahlkonstruktio nen. Rep. No. 088006. Karlsruhe, Germany: Karlsruher Institut für Technologie.

Toasa Caiza, P. D. 2008b. Linear regression analysis for fatigue results and its implementation in the program "Wöhler". Rep. No. Karlsruhe, Ger many: Universität Karlsruhe.

Toasa Caiza, P. D. 2018. "Consideration of runouts in the evaluation of fatigue experiments." Ph.D. thesis, Karlsruhe Institute of Technology.

Toasa Caiza, P. D., and T. Ummenhofer. 2011. "General probability weighted moments for the three parameter Weibull distribution and 
their application in S N curves modelling." Int. J. Fatigue 33 (12): 1533 1538. https://doi.org/10.1016/j.ijfatigue.2011.06.009.

Toasa Caiza, P. D., and T. Ummenhofer. 2018a. "A probabilistic Stüssi function for modelling the $\mathrm{S} \mathrm{N}$ curves and its application on specimens made of steel S355J2+N." Int. J. Fatigue 117 (Dec): 121 134. https:// doi.org/10.1016/j.ijfatigue.2018.07.041.
Toasa Caiza, P. D., and T. Ummenhofer. 2018b. "Consideration of the run outs and their subsequent retests into $\mathrm{S} \mathrm{N}$ curves modelling based on a three parameter Weibull distribution." Supplement, Int. J. Fatigue 106 (SC): 70 80. https://doi.org/10.1016/j.ijfatigue.2017.09.010.

Wöhler, A. 1870. "Über die Festigkeitsversuche mit Eisen and Stahl." Zeitschrift für Bauwesen 20: 73106. 
Karlsruher Institut für Technologie

\section{Repository KITopen}

Dies ist ein Postprint/begutachtetes Manuskript.

Empfohlene Zitierung:

Toasa Caiza, P. D.; Ummenhofer, T.; Correia, J. A. F. O.; De Jesus, A.

Applying the Weibull and Stüssi Methods that Derive Reliable Wöhler Curves to Historical

German Bridges.

2020. Practice periodical on structural design and construction, 25

doi: $10.5445 / I R / 1000123486$

Zitierung der Originalveröffentlichung:

Toasa Caiza, P. D.; Ummenhofer, T.; Correia, J. A. F. O.; De Jesus, A.

Applying the Weibull and Stüssi Methods that Derive Reliable Wöhler Curves to Historical German Bridges.

2020. Practice periodical on structural design and construction, 25 (4), 04020029.

doi:10.1061/(ASCE)SC.1943-5576.0000506 